\title{
A Cascaded H-Bridge BLDC Drive Incorporating Battery Management
}

\author{
K. D. Wilkie, D. A. Stone, M. P. Foster, C. M. Bingham \\ The University of Sheffield \\ Dept. of Electrical and Electronic Engineering, Mappin Street, \\ Sheffield, UK \\ Tel.: +0/44 - 01142225847 . \\ Fax: $+0 / 44-01142225196$. \\ E-Mail: k.wilkie@sheffield.ac.uk
}

\section{Keywords}

$<<$ Multilevel converters $>><<$ Adjustable speed drive $>><<$ Permanent magnet motor $>><<$ Battery management systems $>><<$ Hybrid electric vehicle (HEV) $>>$

\begin{abstract}
A multilevel BLDC drive is proposed using cascaded H-bridges with isolated sources to provide superior output waveforms and reduced current ripple whilst incorporating observer based SoC estimation. Energy management, based on SoC, is incorporated to improve battery performance, reduce variation between cells and to control charge/discharge profiles.
\end{abstract}

\section{Introduction}

Increasing fuel prices, environmental concerns and the possibility of emission related taxes are making the zero emission electric vehicle (EV) an attractive alternative to traditional petrol- and dieselinternal combustion engine (ICE) counterparts. However, the current state of technology does not provide a cost-competitive solution. An interim solution is the hybrid electric vehicle (HEV) with increased efficiency and economy over ICE vehicles. Nevertheless, problems attributed to the electrical energy store, typically a battery pack, include variations between cells and exposure to different charge and discharge rates, leading to unequal states of charge $(\mathrm{SoC})$ of batteries within the pack. Over extended cycling this can cause premature failure of the pack due to the over- or undercharging of individual cells.

With the reduction in cost of rare-earth permanent magnet material, brushless PM motors are becoming preferred candidates for traction applications, as in the HEV. However, the requirement for increasing power density, favouring high-speed low torque geared solutions, is leading to a relative reduction in the inductance of the machine. This places more stringent demands on the electric drive to produce acceptable current ripple without the use of external inductors. Commonly, the switching frequency of the inverter is increased to reduce current ripple but this has limitations by virtue of the switching devices employed and their associated losses.

Recently the Reliable Highly Optimised Lead Acid Battery (RHOLAB) [1] programme has investigated replacing the Ni-MH battery bank commonly found in a HEV, with lead-acid batteries which, in conjunction with a battery management system to condition and optimise performance, will significantly reduce the cost of the battery system. The management system removed individual cells and conditioned them to maximise $\mathrm{SoC}$ by preventing build-up on the plates, thus addressing the problems of variation between the cells but adding an additional system to the motor drive.

In this paper a cascaded H-bridge multilevel converter (MLC) is employed to integrate the battery management system within the motor drive power electronics. 


\section{Cascaded H-Bridge MLC}

A multilevel converter drive for Brushless DC motors is proposed using the cascaded H-bridge topology shown in Figure 1. The cascaded H-bridge multilevel topology isolates individual battery cells, thereby facilitating individual cell monitoring. The vehicle management system can then take $\mathrm{SoC}$ into account during operation, to perform charge balancing, to optimise cell performance and to initiate remedial action should a cell catastrophically fail.

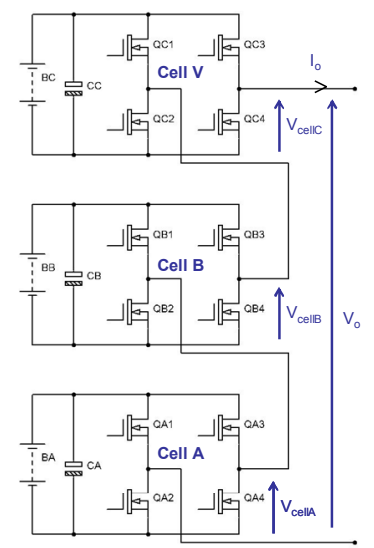

Figure 1: 7-level Cascaded H-bridge

The multilevel converter produces PWM output from a single cell at a time, so $\mathrm{dv} / \mathrm{dt}$ is reduced, decreasing the filtering requirements and common mode and bearing currents that have been linked to mechanical failure [2,3]. The current ripple in the machine is also reduced, by switching a greater number of lower voltage levels, either improving the torque characteristic of the drive or allowing for the use of higher power density, lower inductance machines. When used with a BLAC motor, nearsinusoidal waveforms can be generated with or without high frequency PWM.

Sources [4-6] that investigate multilevel converter performance, topologies, applications and modulation strategies agree on further fundamental advantages of the multilevel converters not specifically covered here, such as the reduced voltage stress of the switching devices and harmonic distortion with more accurately synthesised output waveforms.

In a more specific paper for this application [7], the use and analysis of a multilevel DC drive for low inductance machines is presented using the multilevel converter to modulate the DC link of a sixswitch inverter. However, this does not consider the effect of operation on battery SoC. The work cited in [8] specifically presents methods of balancing discharge and charge equalisation but does not include the implementation of SoC estimation. This paper will expand on ideas from each, producing reduced current ripple and charge balancing with the addition of battery management as well as SoC estimation, within a motor drive.

Unequal source voltages, such as those encountered with battery packs, are considered in [9] with a method presented to calculate switching angles to minimise total harmonic distortion. The proposed drive is focussing on equalising these voltages rather than minimising the harmonic distortion caused by the unequal sources.

The cascaded multilevel converter has a natural fault tolerance, where, if any cell should fail, it can be bypassed by switching on a pair of high side or low side switches depending on the fault, and the converter will continue to operate with the output voltage reduced by only a single cell voltage.

SoC estimation will be based on observer techniques to provide an accurate $\mathrm{SoC}$ indication without requiring either initial calibration, or suffering from the cumulative errors caused by integration techniques. 
The proposed BLDC drive system, shown in Figure 2, consists of three isolated H-bridge cells each with a $12 \mathrm{~V}$ battery, phase controller, standard six-switch inverter providing commutation, and driving a BLDC $1.2 \mathrm{~kW}$ motor. With the six-switch inverter providing commutation, only a single phase multilevel converter is required, reducing complexity but allowing development of the battery management algorithms.

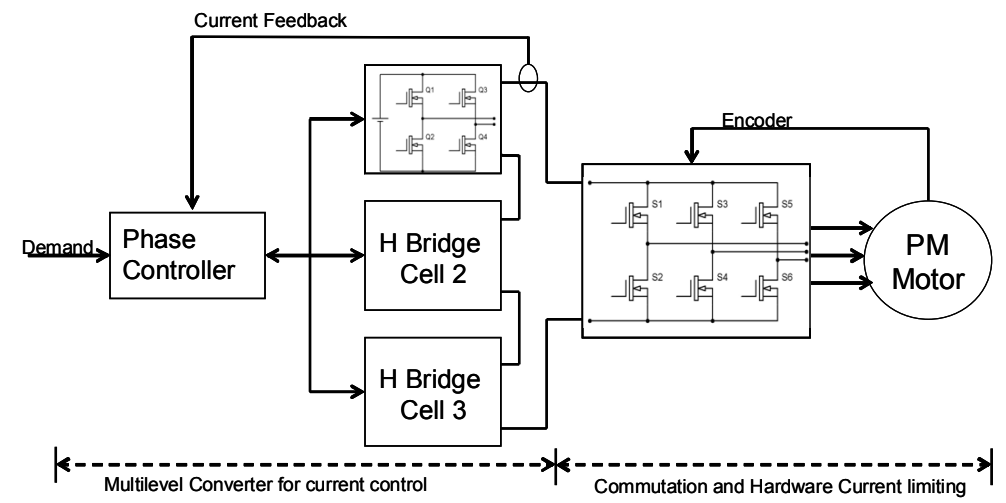

Figure 2: Proposed Multilevel BLDC Drive

\section{Prototype Hardware}

To compare the performance of 2-level and multilevel converters, two prototypes have been constructed. These are shown in Figure 3; (a) shows the 2-level prototype and (b) the 7-level prototype, both being specified to drive the same $1.2 \mathrm{~kW}$, brushless PM machine.

Embedded processors on each of the H-bridge cells produce the PWM signals and implement SoC estimation whilst receiving cell state input from the controller and returning SoC information. The controller calculates the states required to produce the demand and selects which cell produces the output based on the received SoC. Both prototypes use a PIC18F4431 series microcontroller as the embedded processor, with each H-bridge cell using a PIC18F2431 which communicates via an optically isolated SPI interface.

The 7-level prototype consists of three H-bridge cells, (A, B, C) and a phase controller, each H-bridge cell using a $12 \mathrm{~V} 30 \mathrm{Ah}$ sealed lead acid battery. 7 voltage levels are chosen as it provides a significant reduction in current ripple and at least three battery levels are required to evaluate the battery management schemes. However, the construction of the system uses identical cells on a common interface bus providing a modular, readily expandable system with built-in redundancy.

The switching devices used in the 2-level converter are Philips SenseFETs BUK7909 MOSFETs, rated at $75 \mathrm{~V}$ and $75 \mathrm{~A}$. Two MOSFETs are used in parallel for each switch and low side current sensing is implemented removing the need for external sensors. The MLC H-bridge cells use FQA170N06 60V, 150A MOSFETs. For comparison the same switching frequency of $20 \mathrm{kHz}$ is used for both prototypes. 


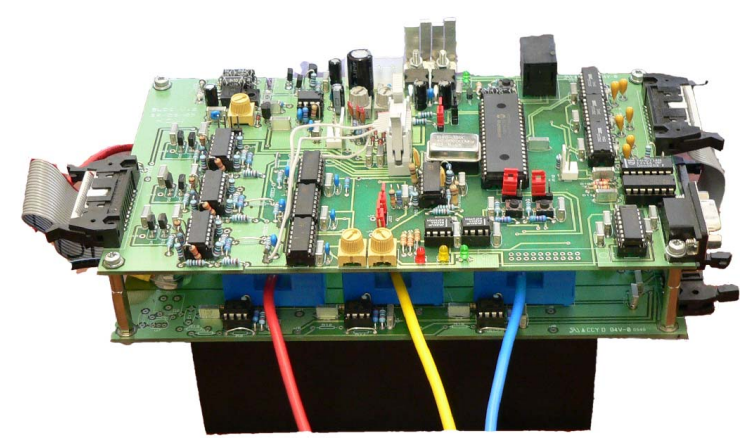

(a)

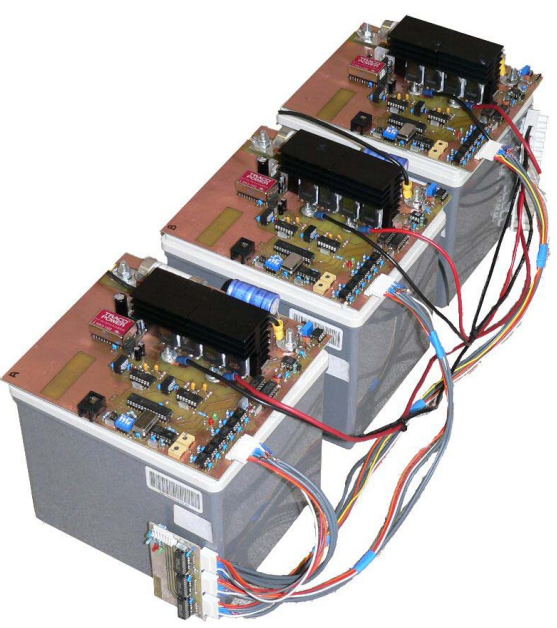

(b)

Figure 3: Prototype Hardware, (a) 2-level converter, (b) 7-level converter

\section{Results}

The following section presents experiment results taken from the prototype hardware in the case of the current ripple comparison and experimental waveforms. Battery management is demonstrated with simulations using Simulink.

\section{Current Ripple Comparison}

The improvement in current ripple is demonstrated by simulation using 2- and 7-level converters. Figure 4(a) shows phase current in a single commutation step of a 1.2kW BLDC machine, while (b) highlights the current ripple on a smaller time scale.

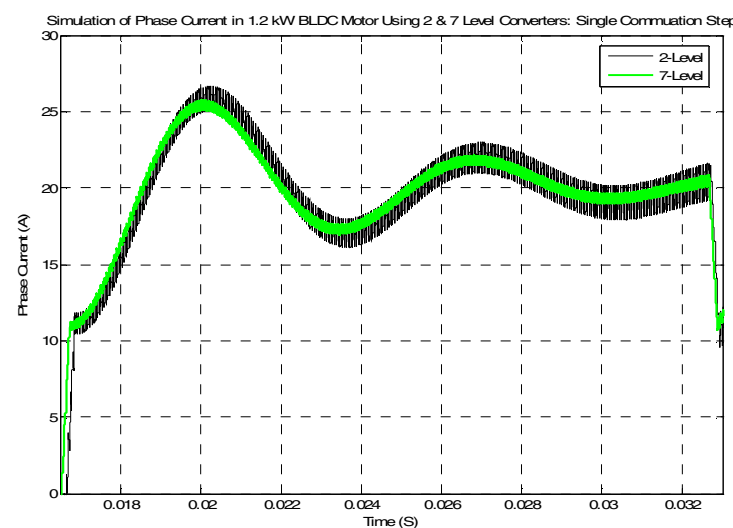

(a)

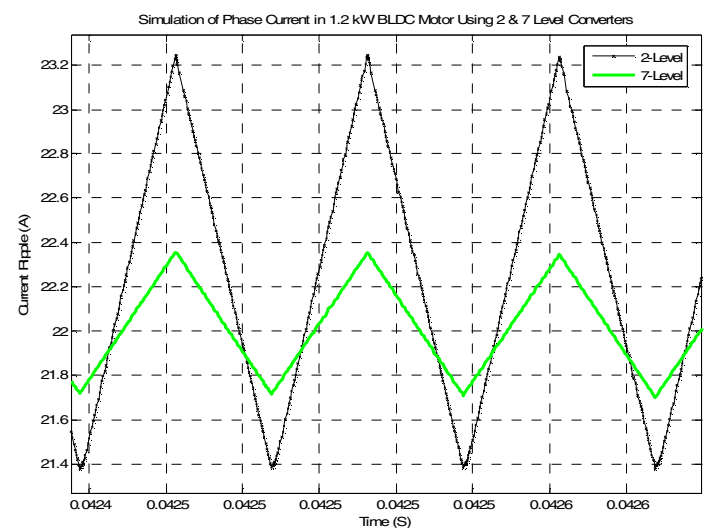

(b)

Figure 4: BLDC Phase Current Simulation, (a) single commutation step, (b) highlighting current ripple

A comparison between calculated, simulation and experimental current ripple is given in Figure 5, showing variation in current ripple with duty cycle. Open loop control is applied to both drives with the current ripple measured as duty is increased. For comparison, current ripple as a function of duty has been determined from Equation (1-4). Figure 5 shows excellent agreement between theoretical prediction, simulation and the experimental results from the prototype converter. 
The current ripple can be calculated by using the motor equations:

ON state

$$
V_{d c}=i 2 R_{p}+2 L_{p} \frac{d i}{d t}+e
$$

OFF state

$$
0=2 i R_{p}-2 L_{p} \frac{d i}{d t}+e
$$

By subtracting (2) from (1) and rearranging leads to $I_{\text {ripple }}$ given by:

$$
I_{\text {ripple }}=\frac{V_{d c} \times \delta}{2 \times L_{p} \times F_{S}}\left(1-\delta^{2}\right)
$$

Where;

$L_{p^{-}}$phase inductance, $V_{d c^{-}}$DC link voltage, $F_{S^{-}}$switching frequency, $\delta$ - duty cycle

This calculation gives the current ripple due to a 2-level converter with a supply $V_{d c}$ and duty cycle 0 $100 \%$, and can be modified for a multilevel converter by noticing $V_{c e l l}$ is $V_{d c}$ divided by the number of levels. Although each cell duty cycle varies between $0-100 \%$ the total converter duty only varies between $0-(100 / \mathrm{m}) \%$, where $\mathrm{m}$ is the number of cells. The current ripple equation for the 7-level multilevel converter, where $\mathrm{m}=3$, is given by:

$$
I_{\text {ripple }(7 L)}=\frac{V_{\text {cell }} \times \delta}{2 \times L_{p} \times F S}\left(1-3 \delta^{2}\right)
$$

The 7-level converter has three maximum points when a cell is producing $50 \%$ duty cycle and two minimum points when a cell voltage or integer multiple cell voltage is applied. Clearly, the 7-level multilevel converter has a much lower current ripple with the calculated values agreeing closely with experimental results thereby providing lower torque ripple and superior motor performance. 


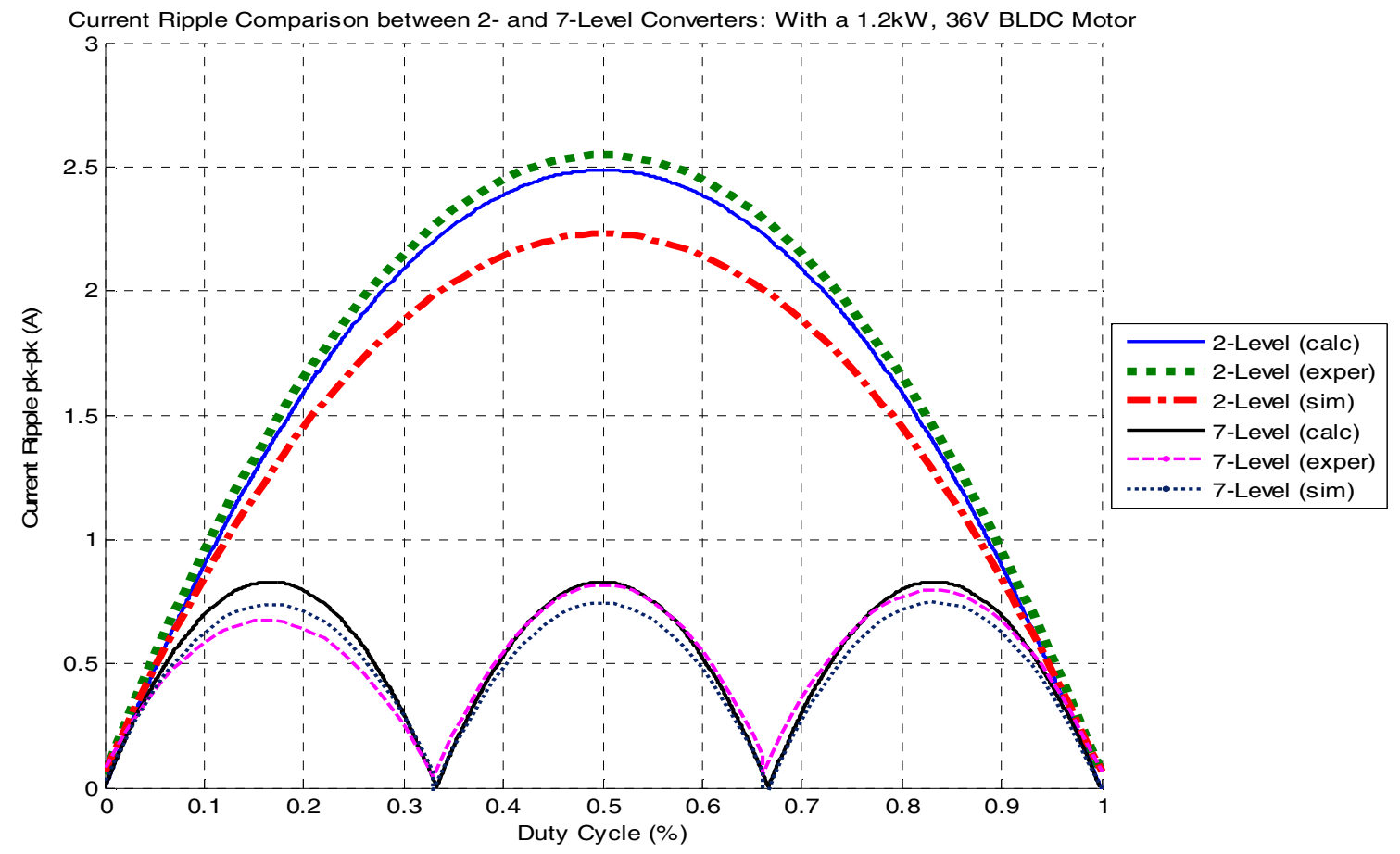

Figure 5: Current Ripple Comparison

\section{Battery Management}

Battery cells are commonly connected in series forming a battery pack in which performance, due to parameter variation and ageing effects, can deteriorate over time as the pack is exposed to different charge and discharge rates as well as variation of SoC within the pack.

The effect of multilevel operation on battery SoC has been investigated in simulations, using Randles' equivalent circuit of a lead acid cell presented in [10] to model the battery and SoC estimation based on the bulk capacitance voltage $\left(V_{c b}\right)$.

Since it is unlikely that the batteries used in the multilevel converter begin with the same initial conditions, it is important for the battery management scheme to accommodate initial variations as well as the limitation with multilevel converters where the lowest level cell becomes discharged most quickly as in Figure 6 (a). Implementing lowest SoC last and then using switch pattern rotation the battery $\mathrm{SoC}$ can be equalized before a balanced discharge Figure 6(b) occurs. This is based on methods presented in [8] and applied to battery SoC estimation.

The simulation results presented in Figure 6 show the battery SoC in the 7-level converter, (a) with, and (b) without battery management. This is with an equivalent load resistance of $1.08 \Omega$ and the converter producing $75 \%$ of its rated output voltage. It is inadvisable to discharge lead acid batteries below $50 \% \mathrm{SoC}$, which, from Figure 6 gives 22 minutes of running time for an unmanaged system or nearly double that at 42 minutes with battery management. 


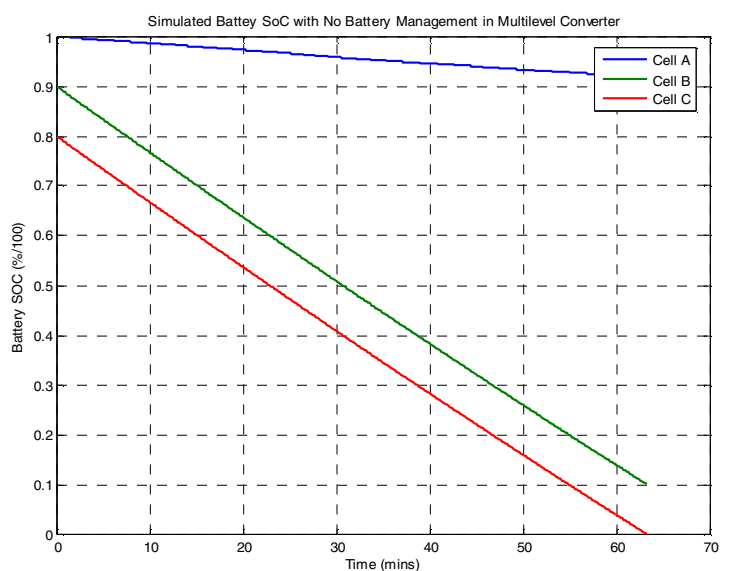

(a)

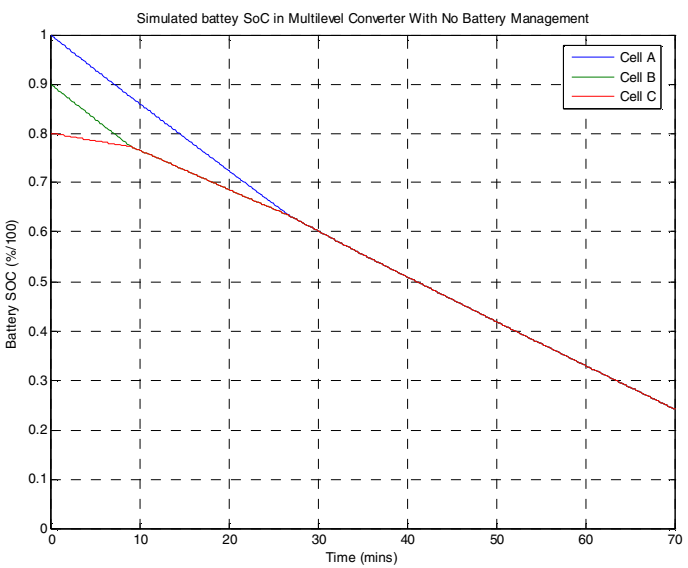

(b)

Figure 6: Battery SoC, (a) no battery management, (b) with battery management

\section{Experimental Waveforms}

A typical 7-level converter waveform is shown in Figure 7, with converter demand at $50 \%$ rated output voltage, Cell A is producing $V_{\text {cell }}$, cell B a $50 \%$ duty PWM signal and cell C appearing as a short circuit. The combined output voltage appears in the bottom graph as a $12 \mathrm{~V}$ PWM signal offset by $12 \mathrm{~V}$. The current is also shown, which is the DC link current into the six-switch inverter.
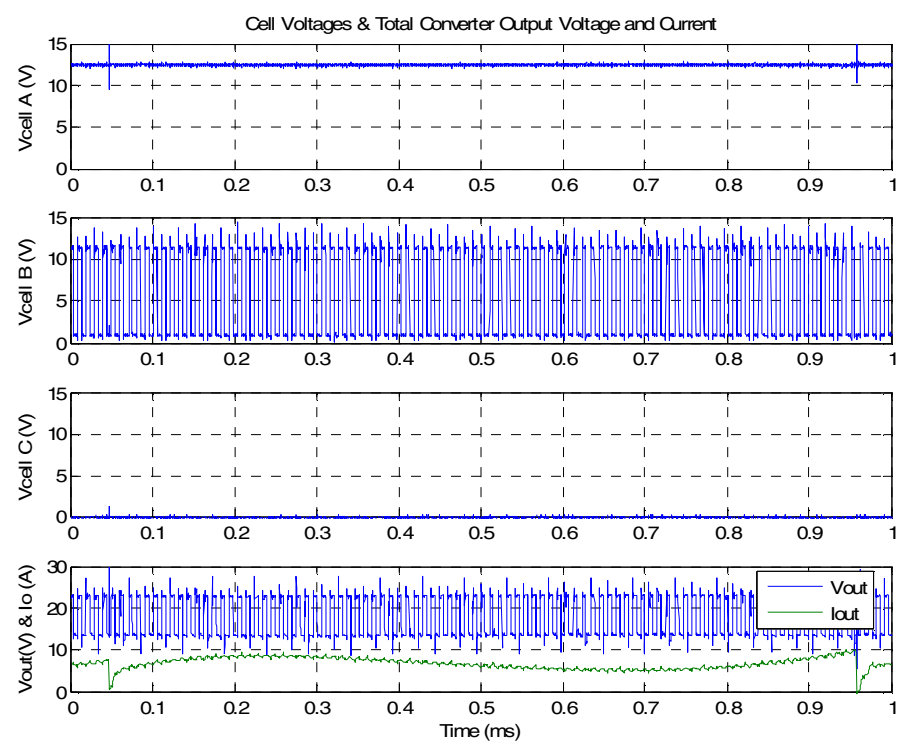

Figure 7: Output Cell Voltages and Combined Converter output

BLDC motor waveforms for a 2 and 7- level converter are shown in Figure 8 with both converters producing $50 \%$ rated output. Importantly at 50\% output, both converters have maximum current ripple, however, the current ripple is noticeably smaller in the 7-level situation. The phase voltages are shown in the upper graph with the 2-level producing $0-V_{d c} \mathrm{PWM}$ and the 7-level producing $12-24 \mathrm{~V}$ PWM. 

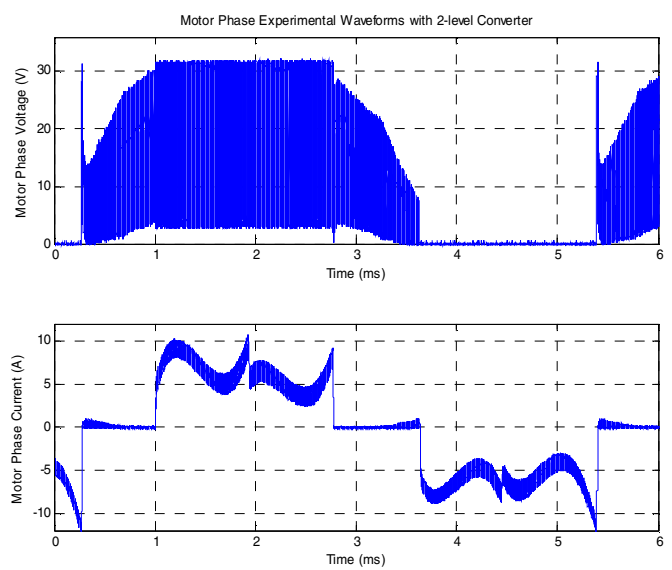

(a)
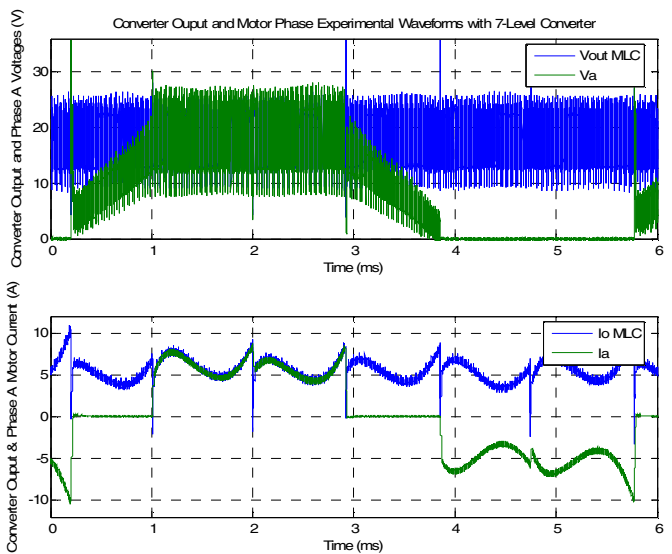

(b)

Figure 8: BLDC Motor Waveforms, (a) 2-level (b) 7-level

Figure 8(b) shows the motor phase current as well as the multilevel converter output current. This can be used to implement current control with a single current sense as all three phase currents are measurable at a single point.

\section{Discussion}

A multilevel BLDC has been presented, with experimental results, to demonstrate the reduced current ripple achievable when compared to 2-level converter; simulation results show further improvements are possible with the incorporation of battery management.

The converter is capable of producing BLAC waveforms as each of the H-bridge cells consists of a full H-bridge cell rather than the reduced half bridge presented in [7]. With construction of two more phases a BLAC system can be produced implementing the same battery management techniques.

The observer based SoC estimation still requires implementation on the H-bridge cells to confirm the operation of the battery management with experimental results.

\section{Conclusion}

The proposed drive offers a superior output waveform and reduced current ripple by comparison with the standard 2-level converter commonly used. The inclusion of observer based SoC estimation and implementation of battery management algorithm has been demonstrated, to improve battery performance by reducing the variation between cells. The multilevel converter prototype will allow for development of the battery management algorithm and provide comparison to the 2-level converter.

\section{References}

[1] A. Cooper, "Development of a lead-acid battery for a hybrid electric vehicle," Bangkok, Thailand, 2004.

[2] J. M. Erdman, R. J. Kerkman, D. W. Schlegel, and G. L. Skibinski, "Effect of PWM inverters on AC motor bearing currents and shaft voltages," IEEE Transactions on Industry Applications, vol. 32, pp. 250-259, 1996.

[3] F. Wang, "Motor shaft voltages and bearing currents and their reduction in multilevel medium-voltage PWM voltage-source-inverter drive applications," IEEE Transactions on Industry Applications, vol. 36, pp. 1336-1341, 2000.

[4] R. Teichmann and S. Bernet, "A comparison of three-level converters versus two-level converters for low-voltage drives, traction, and utility applications," IEEE Transactions on Industry Applications, vol. 41, pp. 855-865, 2005. 
[5] J.-S. Lai and F. Z. Peng, "Multilevel converters - a new breed of power converters," IEEE Transactions on Industry Applications, vol. 32, pp. 509-517, 1996.

[6] J. Rodriguez, J.-S. Lai, and F. Z. Peng, "Multilevel inverters: A survey of topologies, controls, and applications," IEEE Transactions on Industrial Electronics, vol. 49, pp. 724-738, 2002.

[7] G. J. Su and D. J. Adams, "Multilevel DC link inverter for brushless permanent magnet motors with very low inductance," Chicago, IL, 2001.

[8] L. M. Tolbert, F. Z. Peng, T. Cunnyngham, and J. N. Chiasson, "Charge balance control schemes for cascade multilevel converter in hybrid electric vehicles," IEEE Transactions on Industrial Electronics, vol. 49, pp. 1058-1064, 2002.

[9] L. M. Tolbert, J. N. Chiasson, K. J. McKenzie, and Z. Du, "Control of Cascaded Multilevel Converters with Unequal Voltage Sources for HEVs," IEEE, pp. 663-669, 2003.

[10] B. S. Bhangu, P. Bentley, D. A. Stone, and C. M. Bingham, "Observer Techniques to estimate the State of Charge of Valve Regulated Lead Acid Batteries for Hybrid Electric Vehicles," presented at IEEE Proceedings Vehicle Power and Propulsion, Chicago, 2005. 